Article

\title{
'Resources to Needs': A Paradigm for Addressing the Potentiality of the Urban Volume
}

\author{
Michael Robert Doyle \\ Laboratory of Environmental and Urban Economics, École Polytechnique Féderale de Lausanne, 1015 Lausanne, \\ Switzerland; E-Mail: michael.doyle@epfl.ch
}

Submitted: 9 September 2016 | Accepted: 13 February 2017 | Published: 7 March 2017

\begin{abstract}
Underground resources are often addressed only out of necessity, leading to conflicts between uses and missing opportunities for productive synergies. The Deep City project is exploring a paradigm of 'resources to needs', which considers resource potentials prior to specific urban projects or plans. Mapping is central to the project and has been explored in several cities around the world. The 'resources to needs' paradigm, however, has received little theoretical or philosophical attention. To think resources before needs challenges common urban normative models and the process-oriented thinking of mechanical and ecological paradigms popular today. Where current methods for mapping the underground tend to enroll elements in a particular performance or resource use, Deep City seeks to facilitate an intermediate stage in which resource potentials can coexist without any pre-existing interaction or relationship. To think about the urban volume this way, this article works with the informational motor proposed by French philosopher Michel Serres. The logics of substitution and circulation of the map and its contents helps to think an alternative form of mapping in which the map itself becomes a reservoir of potentiality for thinking the urban volume less in terms of predefined functions and processes than a mass to be collectively cultivated.
\end{abstract}

\section{Keywords}

city models; contingency; information theory; mapping; Michel Serres; potentiality; underground resources; urban underground

\section{Issue}

This article is part of the issue "Urban Forms and Future Cities", edited by Luca D'Acci (Erasmus University Rotterdam, The Netherlands), Tigran Haas (KTH Royal Institute of Technology, Sweden) and Ronita Bardhan (Indian Institute of Technology Bombay, India)

(C) 2017 by the author; licensee Cogitatio (Lisbon, Portugal). This article is licensed under a Creative Commons Attribution 4.0 International License (CC BY).

\section{Introduction: The Deep City Project}

Urban planning and theory has historically treated the mass of the underground as a support or infrastructural system for life on the surface. In practice, the development of the subsurface has responded to the pressing needs of the urbanization of the surface. This approach of exploiting resources out of necessity has led to problems like ground subsidence from uncoordinated aquifer management and building construction in the cities of Paris and Mexico City (Blunier, 2009; Ortiz-Zamora \& Ortega-Guerrero, 2010). The uses of the underground are often managed separately by departments and dis- ciplines that rarely develop common strategies addressing the multiple uses, opportunities and risks of the underground. The Deep City project at the École Polytechnique Fédérale de Lausanne in Switzerland was founded by an interdisciplinary team in 2005 to explore an alternative approach to underground resources, which is sustainable and resilient in its ability to address the multiple uses-excavation for underground space, geomaterials for building materials, groundwater for drinking or irrigation and geothermal energy (Parriaux, Tacher, \& Joliquin, 2004). The team has called the paradigm 'resources to needs' (ressources aux besoins), which promotes a longterm reflection on the potential of the resources and 
the interactions between them prior to orienting their use around a specific need or project (Parriaux, Blunier, Maire, Dekkil, \& Tacher, 2010).

The core objective of the Deep City project has been to develop a mapping method that evaluates the suitability of the geology of an urban area using expert opinion and empirical evidence. The method has been tested and refined on a variety of case studies from Geneva (Blunier, 2009) to Suzhou (H. Li, Li, Parriaux, \& Thalmann, 2013), San Antonio, Texas, Hong Kong, China, and Dakar, Senegal (Doyle, 2016b). While the methodology has moved forward, the Deep City project has given no additional attention to the 'resources to needs' paradigm it promotes. The theoretical framework drew initially on systems theory (notably that of Le Moigne, 1977), which has aided in developing methods for evaluating individual resource suitability, but requires a return to needs when combining the resources in a single map. The case studies of San Antonio (Doyle et al., 2016) and Dakar (Doyle, 2016b) test an alternative combination strategy that addresses the resources not as predefined interacting elements but as mixtures of potential whose uses have yet to be oriented towards any particular need. However, the theoretical and philosophical reflection underlying this strategy has yet to be explored in depth.

This article explores the resources to needs paradigm of the Deep City project, looking at the map as the key object around which a conversation on the potential of the urban volume can revolve. Mapping of the underground resources tends to be limited by the normative city models it consciously or unconsciously adopts and the processes it considers invariant. The normative models of the city of faith, city as a machine, and the ecological city (Shane, 2005) continue to condition the way in which the underground is addressed by urban planning and mapping. The mechanisms upon which these models operate can be understood as motors, particularly the vectorial motor of mechanical transport and the transformational motor born from thermodynamics. Increasingly popular theories today, notably actor-network (Latour, 2005) and assemblage theory (De Landa, 2006), adhere to these two motors. French philosopher Michel Serres proposes a third motor, the informational motor, founded notably on the work of physicist and information theorist Léon Brillouin (Brillouin, 1962/2013; Serres, 1977).

The article will begin by discussing the first two motors according to Serres and their roles in urban normative models before turning in the second section to the informational motor and its alternative logic of substitution and circulation. Then, the urban volume will be defined as an economy of communication, founded upon avoidance and encounter between not just people, but also the urban form and its underlying geology. Finally, the article will return to the resources to needs paradigm, examining how it seeks to address mass prior to its differentiation as matter. The map is described not as a passive representation of underground potential, but as a compass with directionality without direction-potentiality without prescription.

\section{Motors and Models: Transport and Transformation in Urban Models}

Normative models address a single or limited number of dynamics. Michel Serres addresses these dynamics as drivers or motors, of which there are three (Serres, 1977). The first is vectorial; the second is transformational. The vectorial motor is a machine, a transfer of forces. It transports. Its central concern is movement, a movement in a reversible time. From home to work, to the grocery, back home-eternal return. It is epistemic, viewed from a single point. The second motor was born with the thermodynamics of Carnot-from a difference in temperature comes a change in state. It is an apparatus, a system. It is no longer about the movement of single elements, but the flow of the mass. From difference comes transformation. It is diastemic, an irreversible change between states.

Each motor needs a reservoir, which precedes the cycle and the circulation. It is an invariance. In the 1970s, biologist Jacques Monod concluded by looking at cellular reproduction that this invariance precedes necessity. The work to avoid the dissolution of a system or organism originates in a chance event. As the event repeats, the structure of the system evolves and stabilizes around a new state, with no other 'goal' than the fight against a lasting, irreversible (thermodynamic) death. The repetition of the event (of the invariance) requires a transfer or preservation of information that can be constantly read back. Monod observed that the transfer of this information was never perfect (leading either to the evolution or collapse of the system) and concluded, looking at the work of French physicist Léon Brillouin, that such a perfect transfer was physically and statistically impossible. The fact that a system (or organism) maintains its structure - that is, to transfer information with only minimal loss-is so highly improbable that in fact all beings should be regarded as the result of high improbabilityas 'strange objects'. ${ }^{1}$ For Monod, the ultimate reservoir is chance (Monod, 1972).

The reservoir is the beginning of the chain, the arche. This sense is captured in the architectural notion of architectonics. However, where for architectural theory the origin (or arche) can be identified ${ }^{2}$, this is not the case for Monod nor for Brillouin, for whom the source and origin of invariance is forever out of reach. Serres borrows from the architectonic model of Roman architect Vitru-

${ }^{1}$ See Monod, 1972, Chapter 1, entitled "On Strange Objects".

2 Daniel Payot (1982), for instance, understands the arche in architectonics as an immediate source of authority ["le commencement et l'autorité sans distance" (p. 58)], where Serres addresses, from his reading of Monod and Brillouin, as a cipher, whose original meaning has been lost in the mechanisms of reproduction. These latter can be understood as the tekton in architectonics, which for the roman architect Vitruvius is the site of articulation of the arche ["la scène où joue l'archè" (p. 65)]. 
vius, the concepts of the ichnographia, skenographia, and orthographia, in exploring the dynamics of the three motors in relation to the work of Monod, Brillouin and information theory (Bühlmann, 2016a). The reservoir is the ichnography, void of project like footprints in the sand whose origin has been partially erased by time and tides. ${ }^{3}$ The ichnography is informational entropy-a mass of information with no meaning or value. The motors that draw from the ichnography generate scenographies, particular viewpoints (episteme). ${ }^{4}$ The scenography can be understood as a message intuited from the noise - the path detailed by Brillouin from information to negentropy (or information to which meaning has been ascribed) and back.

A tension exists between ichnography and scenography that is synonymous to the one between the footprints left in the sand (the material trace or graphein) and the attempts to tell their story in language (logos). ${ }^{5}$ The orthography can be understood as that which encodes traces of the 'original' noise (the entropy or ichnography) but which does not adhere to any single scenography (negentropy). For Monod, this orthography would be the genetic code, which carries the traces of past invariances. For Brillouin, it is the informational fringe that accompanies any message and precludes the possibility of a single interpretation. Serres devotes his Foundations series (Rome, Statues and Les origines de la géométrie) to the orthography in the recurring figure of Hestia, as that which stands in (as a statue, gnomon or victim) for a multiplicity of scenographies, and where the two faces of information, knowledge (negentropy) and ignorance (entropy), mingle. ${ }^{6}$

Urban theories of city form tend to reflect a model or scenography. Drawing on a history of normative models and theories, from Sebastiano Serlio to Kevin Lynch and Spiro Kostof, urbanist David Grahame Shane identifies three recurring models: the city of faith, the city as a machine and the ecological city (Shane, 2005). The city of faith organizes its form around a ceremonial center. Its geometry draws on the divine as source of meaning and direction on earth (its arche). Its motor mediates and transports the values or norms of a society. The divine constitutes a reservoir from which a cosmological scenography is drawn by a unidirectional motor. Even if the city of faith is still very present in evolving notions of the divine, ${ }^{7}$ the city as a machine remains the dominant normative model of our era. Where the city of faith is centered on stability, the city as a machine is a system of flows to be rationalized and programmed. Functions are separated following a logic of optimization and linked by communication networks separating different forms of transport. The reservoirs of the vectorial motor are multiplied and linked by movement networks. Activities are distributed in accordance with particular reservoirs, not only in terms of distance for movement but also within an overall balance between points of production, extraction and exchange. ${ }^{8}$

The ecological model addresses the city as an organism, where urban actors "struggle to maintain a delicate, 'organic' balance" (Shane, 2005). Borrowing from cybernetics and $19^{\text {th }}$ century thermodynamics, the city is viewed as an organism whose metabolism drives towards "balanced flows of energy and materials between the human and natural subsystems of the material realm" (Moffatt \& Kohler, 2008, p. 249). Its reservoir's driving force (puissance motrice) is the natural world, perceived as a benevolent force balancing destructive and conservative forces (Cuddington, 2001). This balancing force has often been perceived as synonymous with mathematical equilibrium, which addresses a system's puissance motrice as equations of inputs and outputs and resembles the flow and movement-oriented approach of the city as machine. Challenging this approach, 'the new ecology' underlines the importance of non-equilibrium in the balance of nature (Pickett, Cadenasso, \& Grove, 2004). Rather than operate purely upon flows of certain quantities of matter, this approach focuses on the processes and performances of natural and human elements in an ecosystem. Everything, however, has a role and plays a part. Relationships that are considered unnecessary are excluded from the system.

\section{The Urban Underground in Normative Models and Current Mapping Methods}

The underground appears differently in each of these models. The city of faith sees the underground as a place of death or rebirth and purification. It is for the most part excluded from the city (which is oriented towards the heavens) or limited to ritual acts. As the main reservoir (the ultimate arche) is the ceremonial center, tied to otherworldliness, the underground is addressed according to local myth and practice (Shane, 2005). With increasing industrialization, the earth's subsurface was subjected to a mechanical logic of reservoirs from which resources were extracted for transport and transforma-

\footnotetext{
${ }^{3}$ The word ichnography (ichnographia) is composed of the Greek for footprint (ichnos) and trace (graphein), see (Serres, 1982).

${ }^{4}$ Scenographia: from the Greek skene for the stage, later taken up by Vitruvius to mean a viewpoint of a building.

${ }^{5}$ In his reading of the roman poet Lucretius's De Rerum Natura (On the Nature of Things), Serres argues that from the point of view of an atomist physics the ichnography is the chaos cloud with no direction (in French, sens) or meaning (also sens in French, an important double meaning for Serres). This is how scenography can be linked back to the material world and not limited to a logos of human origin.

${ }^{6}$ See, for instance, Rome (1983/2015, Chapter 2, The City of Alba), Statues (1987/2015, Chapter 11, The Statue of Hestia) and Les origines de la géométrie (1993, p. 138, Hestia et l'épistémè).

7 Shane (2005) associates the work of economists Von Thünen (ca. 1826), Weber (ca. 1929) and Alonso (ca. 1964) with the continuation by other symbolic means of this dominant center as a reservoir of wealth through economic exchange of goods produced and sourced from the hinterland. The 'central business district' is a recognizable symbol of the modern relationship to this 'ceremonial' center. For more information on Von Thünen, Weber and Alonso, see also Portugali (2011).

${ }^{8}$ Shane situates the Central Place Theory of economists Walter Christaller and Albert Lösch within the city as machine normative model.
} 
tion. ${ }^{9}$ This logic recalls the spatial relationships explored by early location theory (e.g. Von Thünen and Alonso) of extraction, transformation and distribution to the local market. ${ }^{10}$ The earliest and most well-known reflection on the underground in an urban context is the Rue future of the Parisian engineer Eugène Hénard (Figure 1), which is one of the best examples of both the city as machine normative model and the tendency at the turn of the $20^{\text {th }}$ century to see the city as a unified system (Shane, 2005; Williams, 1990/2008).
With extension of urbanization to the planetary scale (Brenner \& Schmid, 2015), the underground is but one layer of all 'altitudes of urbanization' (Bélanger, 2016). The emphasis by the ecological model on process and performance means that the underground is included where its role is evident-where it has already become meaningful or organized information (negentropy) and is perceived as necessary. It is sometimes labelled in this context as an ecosystemic or infrastructural 'service' (Bobylev, 2009; Bobylev \& Sterling, 2016). Alternatively,

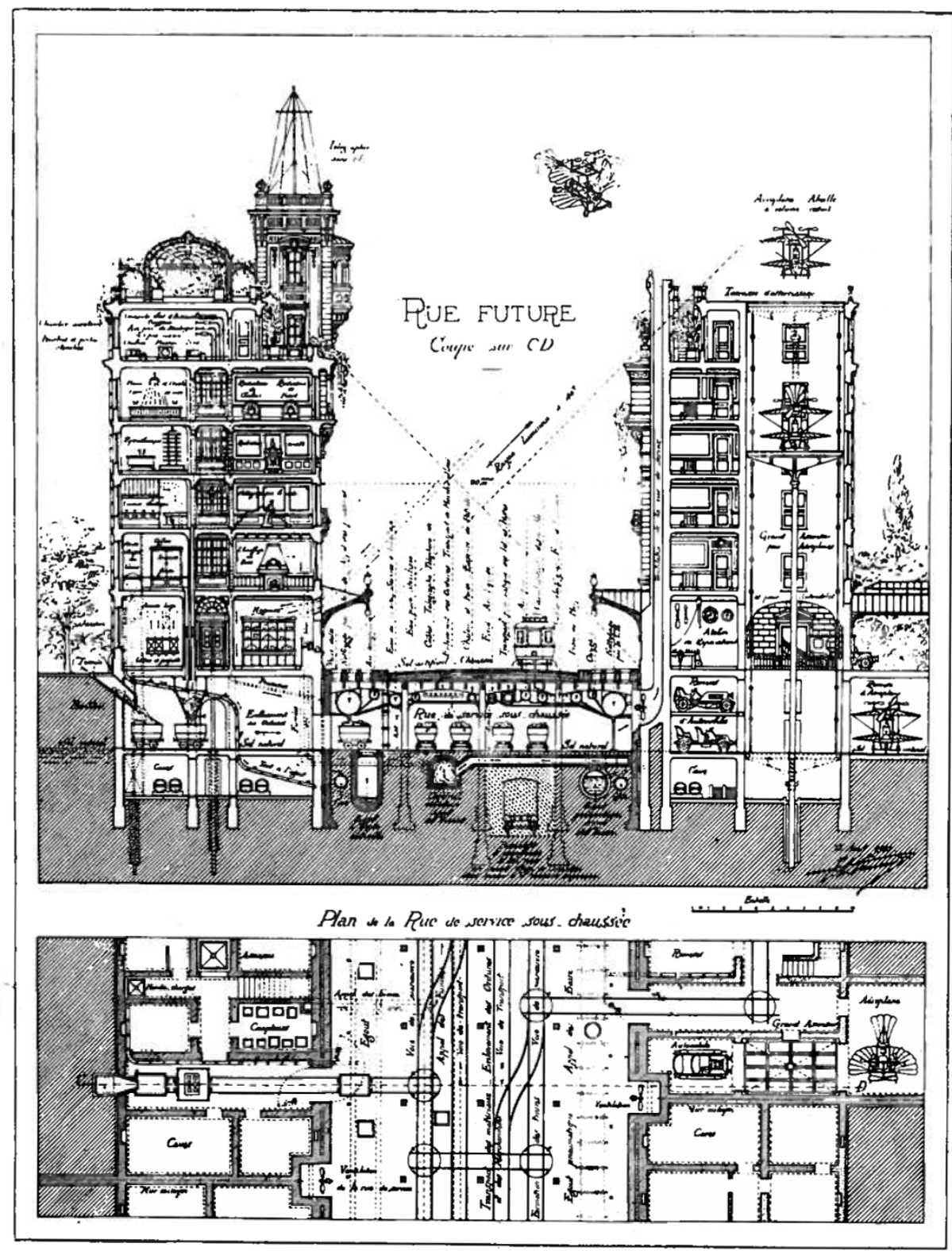

Figure 1. Eugène Hénard's Rue Future (future street) integrating the underground into a mechanical rationalization of flows of materials and people (Hénard, 1903/1982, p. 351).

\footnotetext{
${ }^{9}$ The scientific exploration of the earth's crust did not immediately eclipse the mythical dimension of the underground. With the birth of geological investigations in the $19^{\text {th }}$ century, the earth's crust was equated with a deep time, or an archive of the earth's history. Many people thought geology would turn up the remains of the original sinners having died in the Biblical flood. The bodies that were found, however, did more to support Darwin's theory of evolution. The bodies of extinct species of animals inspired many of the fantastical adventure stories we recognize in the works of Jules Verne (Williams, 1990/2008).

${ }^{10}$ For illustrations and mathematical descriptions, see Portugali (2011).
} 
it is an antagonistic (or 'sacred') force to be avoided and left alone-a source of uncertainty (entropic information) in the construction and planning process. Projects incorporating the underground tend to be oriented towards a single or limited set of pre-defined processes. By placing teleology and necessity at the fore (contra Monod), the ecological model adopts an essentialist approach to the role of function in nature. In this light, Bélanger's illustration of the altitudes of urbanization (Figure 2) could be misconstrued as a detailed account of all possibilities for the urban volume. It is, in fact, only one scenography of the ichnography.

Recent mapping techniques adopt different strategies for providing meaningful information on the underground. Of relevance is the way these strategies identify evaluation criteria and combine them proportionally in the map. The Helsinki and Hong Kong masterplans are both mandated and funded by public entities (Vähäaho, 2009; Wallace, Roberts, \& Lau, 2014). Underground potential is understood as suitability for built space and is based principally on the geological conditions of the city. In both examples, the relationship between the criteria, leading to the identification of zones of high potential (which are further classified in Hong Kong's masterplan), are decided upon by the practitioners (geologists or geotechnical engineers) mandated by public entities. The difficulty of rigorously combining multiple criteria is addressed in the methods adopted in the Chinese case studies of Changzhou, Qingdao and Suzhou (H. Li et al., 2013; Peng, Wang, \& Peng, 2014; Zhao, Peng, Wang, Zhang, \& Jiang, 2016) using the Analytic Hierarchy Process (AHP) (Saaty, 1980). The AHP's use of pairwise comparisons situates the evaluation criteria on the continuous scale, as opposed to the methods adopted by Helsinki and Hong Kong where expert knowledge places criteria on an ordinal scale. ${ }^{11}$

For these recent projects, the maps provide valuable information on the territory-wide geological potential for buildable space. Communicating the suitability for construction is the main message and other information (not included in the evaluation of potential) is removed for legibility, notably the current distribution of urban form or of activities. Other resources (geomaterials, groundwater or geothermal energy) are absent or are included as limiting factors for the space potential. Even Deep City, in its evaluation of underground potential in Suzhou, orients the calculation of potential towards a single resource (space), incorporating groundwater and geomaterials as limiting factors on space potential (see especially $X$. Li et al., 2016). Although the information presented by these maps is undoubtedly valuable for the planning process, it remains oriented towards a pressing need for underground space. In this context, the map remains monofunctional-viewed from a single point (scenographic) and single need. The challenge for the resources to needs paradigm promoted by Deep City is the map's ability to provide information that could have meaning, but has not yet been given any value. To explore this further, and to argue for the map as an orthography, the next section will look at Serres's third-informational-motor.

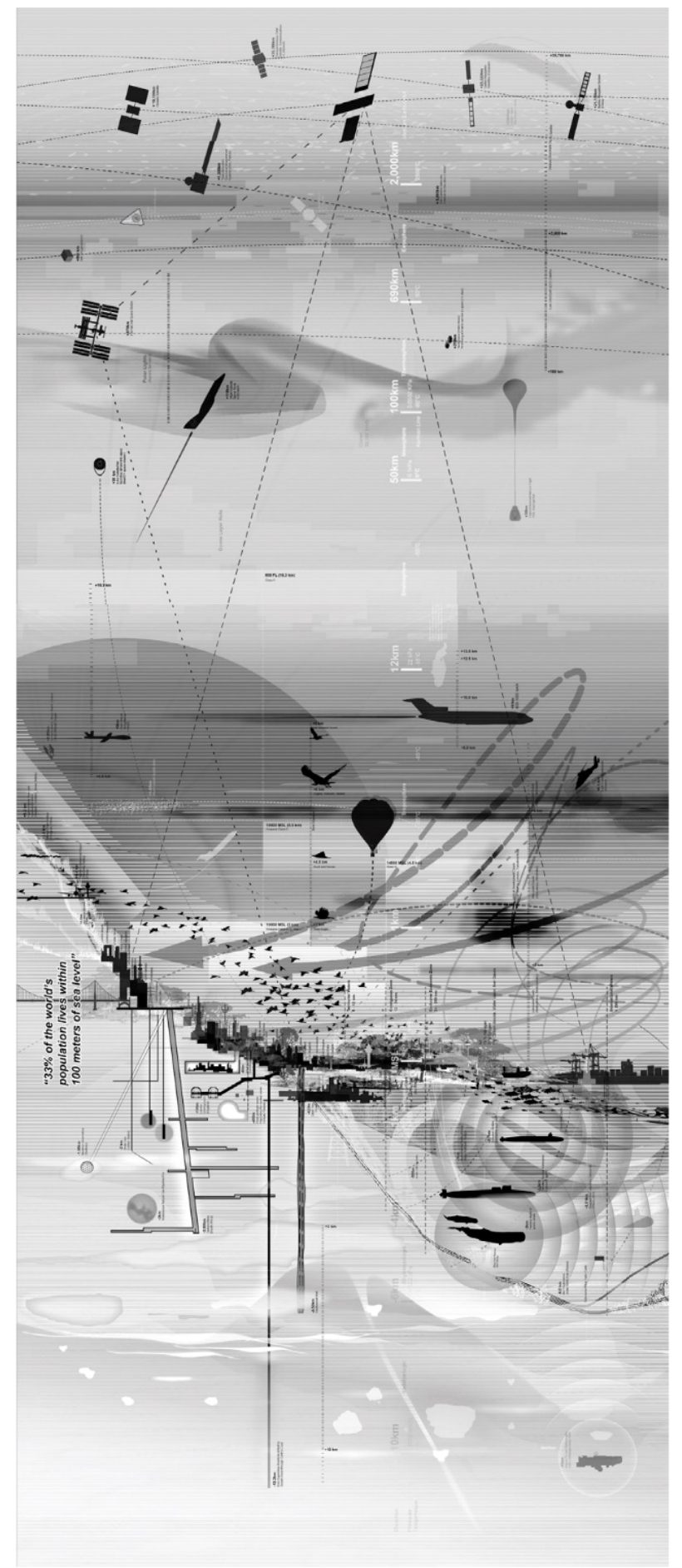

Figure 2. 'Altitudes of Urbanization' captures the many uses observed today in the urban volume, but it would be a mistake to presume that this is an exhaustive account of what the volume could be (Bélanger, 2016, p. 6).

\footnotetext{
11 Lu, Wu, Zhuang, \& Rabczuk (2016) demonstrate in a recent paper how the evaluation of geological suitability using the AHP can be further specified by applying membership functions borrowed from fuzzy set theory to the continuous-scale data.
} 


\section{The Informational Motor: Substitution and Circulation}

Serres's informational motor addresses the dynamics of information-processing established by Brillouin, from noise (entropy) to message (negentropy) and back to noise. If the first generation of motors transports and the second transforms, the third codes (Serres, 1977). It combines the flow of messages with the place-holding, substitutive, roles of markers. Where systems thinking and cybernetics establish fixed roles and relationships between predefined elements, Serres seeks instead a systematization of that which has no (or no recognized) place in the system. ${ }^{12} \mathrm{He}$ is attempting to account for the noise that accompanies every message, to not sacrifice the residual entropy for the sake of a single form of negentropy. Serres views the act of harnessing residual entropy as similar to the role of the parasite, which in French is also the word used for noise on a channel. The parasite is responsible for the bifurcations of mass and meaning (in French, a change in meaning, sens, is also a change in direction, sens) and the contingent introduction of a new meaning to information (producing negentropy in the system) (Serres, 1980/1982). Per Monod, this new information as negentropy has the potential to lead to system collapse ('death') or evolution ('rebirth').

The probable state of a system is therefore not equilibrium, as it would have been for $19^{\text {th }}$ century physical and statistical thermodynamics (the transformational motor), but rather its dissolution and thermodynamic death (Brillouin, 1962/2013). This is the view of equilibrium that is found in non-equilibrium versions of ecology where systems are open (Pickett et al., 2004). For this latter, the open system imports energy or information that it needs and ejects as waste that which it cannot use. The system is evolving to avoid death rather than simply returning to a stable state, in accordance with the second law of thermodynamics. As Brillouin argues, however, this work comes with a cost. The first and second motors try to balance the ledgers, thinking that information can be acquired for free-that it only has value and no cost. The acquisition of knowledge (e.g. measurement) converts entropy into negentropy, but that conversion process releases entropy, or noise. ${ }^{13}$ In exchange for knowledge comes ignorance. ${ }^{14}$

The informational motor accounts for this ignorance by addressing entities in the world (from the living to the nonliving, the natural to the artificial) as black boxes. Black boxes have no identifiable origin, meaning that their arche remains out of reach. Like fading footprints in the sand, only the material trace, the ichnography is left. Rather than attempt to propose a single, mechanical or thermodynamic model (as the vectorial and transformational motors), the informational motor recognizes that there is no model better than the 'thing itself'. The attempt to make sense of the ichnography produces multiple models (points of view or scenographies) and the informational motor attempts to account for the multiplicity of these by embracing the entropic, the as-yet-meaningless or senseless information (Serres, 1977/2000). Scholarly investigation tries to make sense of the city as a black box. From meaningless information (undifferentiated masses), the crowd, community is formed, insiders differentiated from outsiders. Mass is articulated into buildings, streets, squares. Sometimes these acts of articulation and differentiation occur by chance and seem to share no common origin. ${ }^{15}$ Other times, particularly when a single point of view (scenography) is adopted, they are subjected to normative models, imposing an observed or ideal order. Articulation comes with a price-every act of deviation, bifurcation or differentiation of the mass is paid for in the entropy generated by determination. Determination generates indeterminacy (as entropy or the loss of information).

\section{Informational Motors of the Urban: Economies of Communication}

The city, as a black box, is constituted by many hidden agencies. The inadequacy of normative models is their tendency to adjudicate for a limited number of agencies. In response to the weakness and relative inflexibility of the normative models of the city of faith, the city as machine and the ecological city, urban theory departed from holistic models and sought to identify the basic elements comprising the city. Referring to the work of Lynch (1960), Rowe and Koetter (1978) and Paola Viganò (1999), Shane (2005) identifies three main elements that have pervaded elementary thinking: the enclave, the armature and the heterotopia. These elements can be understood as the main agencies of the city as an oikonomia working on the mass of the urban volume. The logics of their combination establish a lawfulness (nomos). The enclave is an element of centralization and concentration, like squares, places, bounded spaces. Its perimeter is often controlled by rules, guardians or walls. The armature is a sorting device, linking the enclaves and organizing the relationships between them. The classic examples are streets, arcades, interior corridors and skyscrapers (vertical armatures). The hetero-

\footnotetext{
12 “Le problème posé ne serait pas un problème logique, celui de la construction d’un système, mais d’un problème plus général: celui du systématisme d'un grand nombre de systèmes possibles. Peut-on passer de ces nouvelles scénographies à l'ichnographie?" [The problem is not a logical one of the construction of a system, but a more general problem of the systematism of a large number of possible systems. Can we move from these new scenographies to the ichnography?, author's translation] (Serres, 1990, p. 16).

13 Even if that cost is a quantum of light, as he argues when working through the ability of Maxwell's demon to "freely" move electrons from one heated chamber to another, in contradiction to the second law of thermodynamics which postulates that systems move towards entropy or molecular disorder (Brillouin, 1962/2013).

14 Literally, it is a "lack of information about the system" and a "disorder in the hidden degrees of freedom" (Brillouin, 1962/2013, Chapter 12).

15 In Rome, Serres (1983/2015) is fascinated by Roman historian Titus Livius's account of the history of Rome and his tendency to recount not one, but many foundational moments. Rome, less so than Athens or Jerusalem, is a city born of contingency and multiple, often hidden or mythical, origins.
} 
topia, borrowed from Michel Foucault, is "a place that mixes the stasis of the enclave with the flow of an armature, and in which the balance between these two systems is constantly changing" (Shane, 2005, Chapter 3). Heterotopias include Foucault's best known examples of the prison and the hospital, but also shopping malls, amusement parks and cruise ships. They challenge the dominant enclave-armature order.

With the armature, enclave and heterotopia, Shane tries to move beyond the limits of morphology and typology - the tendency to produce "detailed classifications of buildings and open spaces" (Moudon, 1994, p. 289). Such libraries and taxonomies of solids and voids offers "a speedy response and a standardized product", but they suffer from "inflexibility, lack of control by the user, [and] the elimination of variety and choice" (Shane, 2011 , p. 128). They tend to fix the identity of the elements of a city, no matter how exhaustive and long the list. ${ }^{16}$ There is a tendency to identify and reproduce types as necessary (rather than contingent) stabilities. This results in a conflict between those typomorphological elements that are allowed or elevated to artistic prominence and those that are considered non-discursive (Hillier \& Hanson, 1984) or developed from a spontaneous consciousness (Cannigia \& Maffei, $1987 / 2001$ ). Adopting fixed types or forms as a language (logos) by which to 'read' the black box (e.g. the city), risks excluding contingently emergent forms that are characteristic less of the negentropic than the entropic. Shane hints at a return to the entropic information that Serres speaks of, arguing that "types emerge from a flow of energy and pressure, engineered by particular urban actors as specific times to deal with particular situations" (Shane, 2011, p. 133). He is aware of the contingency of the typical and morphic. But the motor he constructs with the three elements is a cybernetic (systemic) onecertain places are armatures, some enclaves and others heterotopias and they behave as such. It is a logic of combinatorics, of mechanical movements and 'pressures' that condition situations. It lacks the informational motor's operation of substitution.

Within an informational motor of the urban, the enclave, armature and the heterotopia are like complexions, with the first two, markers and messages, as stocks of negentropy. The heterotopia addresses entropy, that which could threaten the stability of the system. It can be as much about correction (e.g. prisons) as it can be about emancipation (e.g. amusement parks). But as complexions, these 'elements' would be "discrete configurations of the quantized physical system." (Brillouin,
1962/2013). ${ }^{17}$ The enclave expresses 'centrality', the armature 'linearity' and the heterotopia a heterotopiality. In Platonic philosophy, these complexions concern the status of universals, which may be abstract or concrete. An abstract universal is one that is never instantiated in reality or that remains external to a given selection of entities (a set of houses is more or less similar to the ideal House as an archetype) (Ellerman, 2014). Normative city models deal regularly in these ideals, reading cities as machines or ecosystems. Typomorphological work extracts formal or typological stabilities from existing urban forms. Shane's argument highlights the problem of the status of these stabilities once they are applied elsewhere (Shane, 2011). Concrete universals, on the contrary, depend entirely on the context in which they appear and are internal to the given selection of entities (a set of houses establishes the concrete universal of 'House-ness') (Ellerman, 2014).

Investigating the concrete universals of the city challenges methods of scientific inquiry to dive into the shadows of the black box. Because its origin (arche) is hidden (or ciphered), the attempt to decipher its laws or language never eliminates the black box, but shifts it or multiplies it. It is radically contingent (as ichnography or trace). No single epistemology (no single scenography or point of view) can address it in its entirety. It is an economy whose laws (nomos) may be universal, but whose governing order and relationship to a reservoir (oikos) are distributed among the black boxes nested within each other. ${ }^{18}$ The city as a black box encodes laws according to which the informational or entropic mass is differentiated-separated or combined. Differentiations of mass, whether populations of people or the laying or carving of stone, always articulate a combination of encounter (combination) and avoidance (separation) (Koch, 2016). Deciphering the nomos of the black boxes of the city considers the repetitive acts of differentiation as part of a (partially chance-, partially necessitybased) form of shared or common economy-an economy of communication.

The informational motor of the urban, like the other two motors, can be harnessed. The deciphering of the economy of communication seeks to identify the concrete universals of avoidance and encounter. The mass of the urban form encodes these universals in the materiality of the city. Spatial practices operate on this mass and contingently recode and decipher the ichnography. In the act of deciphering, given the fact that this congealing of mass has no single logic, lies the potential for multiple meanings, recoding, and algebraic substitutions. ${ }^{19}$

\footnotetext{
16 Christopher Alexander's Pattern Language (1977) identifies 253 patterns.

17 Brillouin conceived of entropy as the integral of these complexions. It is therefore potentiality, the "entropy of the system" which is an "extremely large, but finite" number (Bühlmann, 2016b).

18 The Greek, oikonomia, from which the word 'economy' stems, refers to "the worldly manifestation of a given order" (Düppe, 2011, Chapter 4). The points of reference for this worldly manifestation were the seasons (oikoi), and ultimately the movements of the sun, around which the laws (nomos) were ordered (Düppe, 2011).

19 This is one of the limits of seeing spatial configuration, or the differentiation of mass in human settlements as governed by a social logic. The economy of movement as Hillier defines it in Space is the Machine (1996/2007) addresses this differentiation of mass as a reservoir for a motor of transport governed by a single scenography and logos (socio-logy). In an economy of communication, the economy as a worldly order is prior to any logos that presumes to speak its language.
} 
Speaking of urban infrastructure, Keller Easterling refers to the ichnography as 'disposition.' It is what is "hidden in the folds of infrastructure space" and is a "latent potential or tendency that is present even in the absence of event" (Easterling, 2014, Chapter 2). Disposition is not a single potential, a single actualization, but rather the bundle of all that could or could not be actualized. Instead of being a limited number of possibilities, potentiality is a spectrum, from which potentials can be discretized and actualized. The significant difference between potential and potentiality lies in the dual potential of being and non-being. Giorgio Agamben gives the example of the shadow of non-being or impotential as that which accompanies potential in potentiality (Agamben \& Heller-Roazen, 1999). In the informational motor, this is similar to the dual of entropy and negentropy, where the latter is always accompanied by the former. If encounter is a potential, avoidance is also a potential and their "saturated relation" (Koch, 2016, p. 76) would constitute the potentiality of the economy of communication.

\section{Mapping of Potentiality: Returning to the Mixture and Delaying Necessity}

The 'resources to needs' paradigm proposed by Deep City seeks to delay the role of necessity in the planning process by divorcing potential from needs, by avoiding concrete universals and by addressing expert knowledge as ciphered. This divorce is accomplished, in economic terms, by removing demand from the equation and looking at the urban volume purely as supply. It is a return to the mass or-in Brillouin's terms - of information that has yet to be given value. The geothermal potential is best described in this way as dependent upon the conductive capacity or thermal gradient of the geologynot in terms of the value it may have for the local market or in relation to existing sources of energy. Furthermore, the interactions between the resources, which are multiple and synergetic or conflictual, are not given or determined. Where other techniques to calculate (and map) underground potential limit other resources (e.g. groundwater) to its interaction with underground spaces, Deep City calculates each separately and then evaluates the degree of similarity of each part of the city to combinations of potentials (Doyle, 2016a; Doyle et al., 2016). The areas of higher combined potentials are areas of interest because they constitute a larger quantity of entropy or uncertainty by containing several potentials whose overlap, or potentiality, increases the number of possible future states for the site (Figure 3).

The urban form (or human articulation of the urban volume) is addressed in the same way. As opposed to

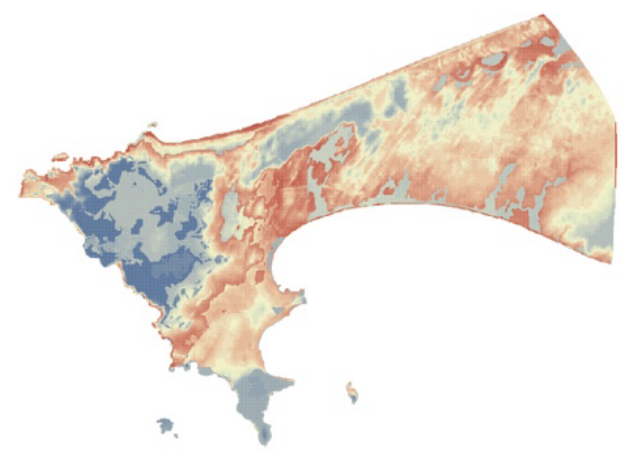

Sp / GM / GW / GT

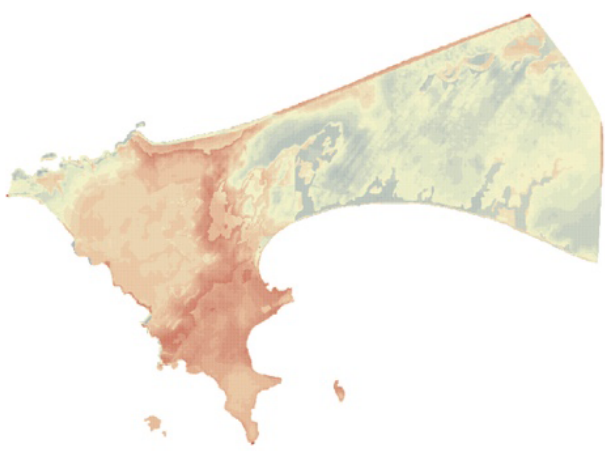

Sp / GM / GW / GT
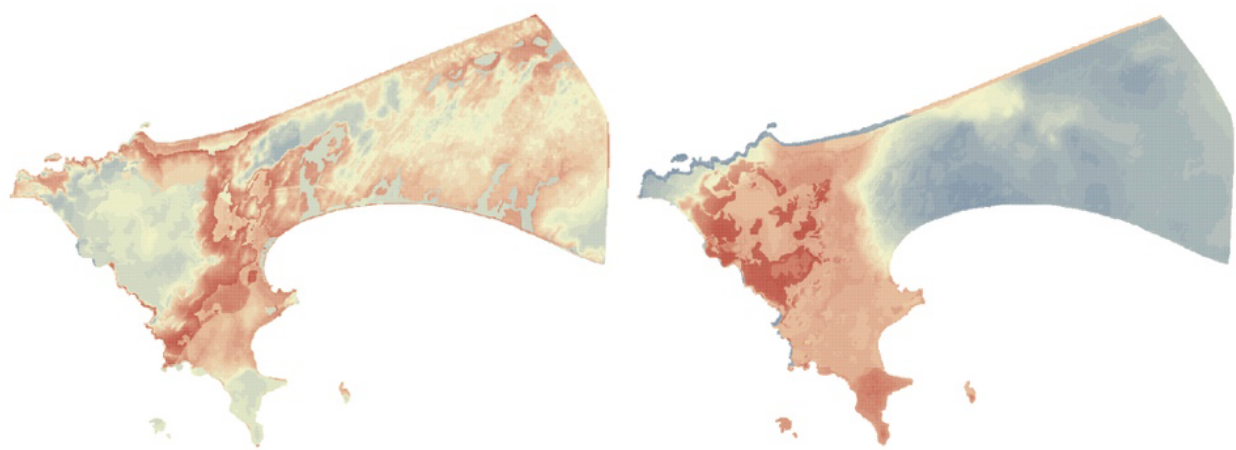

Sp / GM / GW / GT

$\mathrm{Sp} / \mathrm{GM} / \mathbf{G W} / \mathbf{G T}$

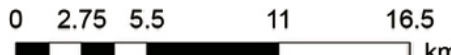
$\mathrm{km}$

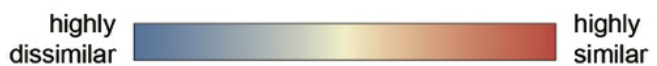

Figure 3. Degree of similarity to different combinations of resource potentials in the city of Dakar (Sp = space; GM = geomaterials; GW = groundwater; GT = geothermal) (Doyle, 2016b, pp. 198-199). 
other mapping methods, the urban form is not indicative of a passive demand, but an entropic supply. Its potential is the cumulative opportunities for encounter or avoidance around a chosen unit (building, parcel, street segment, etc.). Potential in this way is similar to what Lars Marcus calls 'spatial capital' in that it creates "potentials for variations of urbanity" (Marcus, 2010, p. 32), a reservoir or black box of potential. The potential of the urban form is not read as a coherent language, but deciphered as improbable and contingent-as concrete universals. Despite attempts to prove that one or few distances for centrality best account for spatial agency (Hillier, Turner, Yang, \& Park, 2010), centrality is distributed and pervasive (Hillier, 2009). Advocating for one metric is equivalent to making normative claims about the economy of avoidance and encounter (Dovey, 2010). In reality, multiple metrics are needed to capture the diversity of ways in which space is navigated and spatial relationships are articulated. The Deep City project has recently addressed the potential of the urban form using principal component analysis, which identifies invariances in the pervasive centrality of urban form, without resorting to descriptions of spatial configuration from other contexts (Figure 4) (Doyle, 2016b).

Like the previously-mentioned mapping methods tested in China, the Deep City project adopts the An- alytic Hierarchy Process to quantify expert knowledge and to situate evaluation criteria on a continuous, rather than ordinal scale. Simply put, the AHP helps to establish a relationship between elements being evaluated per a set of criteria, chosen in response to a predefined goal (Saaty, 1980; Saaty \& Vargas, 2012). Each element is compared per one criterion, producing a matrix of values that can be normalized and solved to produce an eigenvector. Deep City produces matrices for each resource separately through the comparison, first, of families of geotypes, and then other criteria that contribute to the potential of each resource. However, to delay the role of necessity in contexts in which the value of the underground is not yet given, the overall goal and criteria selected are kept relatively abstract. ${ }^{20}$ The AHP provides a means to address expert knowledge as a black box, as an orthography, to be deciphered. Although the expert (geologist or geotechnical engineer) may be able to place the geological families or criteria on an ordinal scale, the AHP distances the expert from his or own preconceptions (scenography) and reveals the underlying order of evaluation through pairwise comparisons and matrix algebra. ${ }^{21}$

By treating the information on the urban volume in this way, the resulting maps are no longer passive representations of disciplinary knowledge (scenography), but
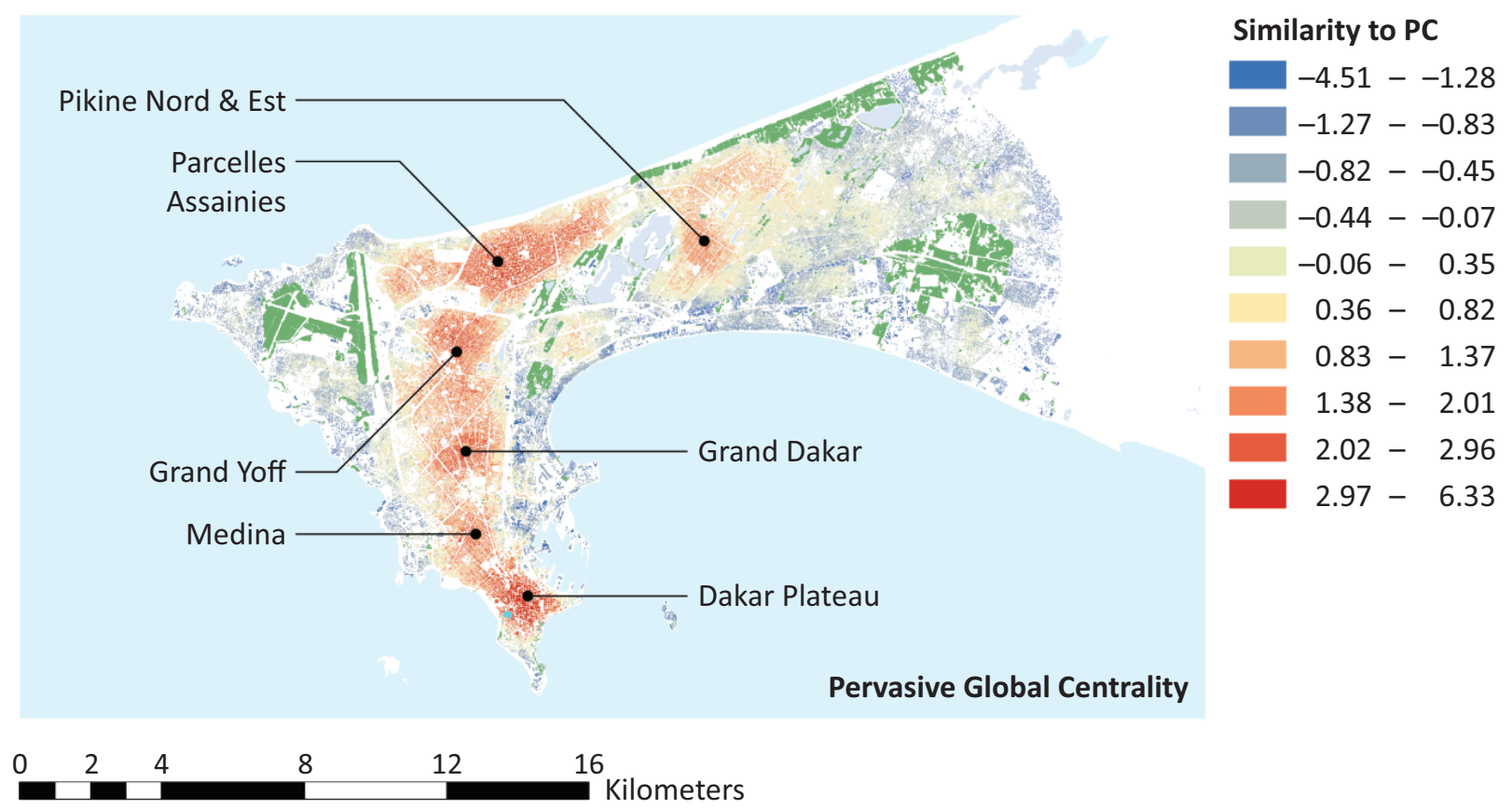

Figure 4. The use of the principal component analysis on centrality analyses conducted at multiple scales identify pervasive centers. The color coding represents (in red) the areas that are the most pervasive to the areas that are least pervasive (in blue) (Doyle, 2016b, p. 190).

\footnotetext{
20 Indeed, when a project is well-defined, a geotechnical engineer would be able to evaluate the bearing capacity of the ground in function of the structure proposed. However, when evaluating potential as a strategic level (on a territorial scale of mapping), many contextual factors are absent and only a general appreciation of potential can be made. This appreciation does not replace, but only precedes, further investigation once a project has been defined.

${ }^{21}$ Rigor is by no means ensured purely by quantification, but by the various controls for inconsistency and sensitivity analysis that can evaluate the responses of the experts and identify areas of dissensus (Saaty, 1990; Saaty \& Vargas, 2013).
} 
an orthography generated by an informational motor. In contrast, mapping using GIS has historically operated within the vectorial motor in accordance with first cybernetics, which "equates it with an exchange and transport of goods" (Poore \& Chrisman, 2006, p. 509), or the transformational motor in accordance with second cybernetics, in which information is transformed through interpretation by the receiver. In both cases, the "real world becomes the source, the map becomes the signal, and the map users are receivers of the message" (Poore \& Chrisman, 2006, p. 513). The map is but a medium, it is not in itself productive of new information. The capacity of mapping to be an information-producing (entropic) agency, independently from quantitative geography's influence from cybernetics, was explored and theorized by the map overlay tradition initiated principally by lan McHarg (Kuitert, 2013; McHarg, 1969) and further theorized in the work of James Corner, for whom mapping stages "the conditions for the emergence of new realities" (2002, p. 216). These conditions are generative of entropy, of an ichnography to be addressed orthographically, rather than scenographically.

This emergence of new realities is, in the informational motor, the role of the parasite or of negentropy in Brillouin's sense of 'free information'. In Rome, Serres refers to free information as a 'white arm', which "has an origin [but] has an undetermined end" (1983/2015, Chapter 3). It is information transmitted with no definite receiver. It is 'white' because it has not yet been interpreted or transformed into a message. It has the possibility to reconfigure relationships as they currently are. Explicitly referring to Serres, Hetherington and Lee (2000) call these white elements 'blank figures'. These figures refuse "to adopt a singular position in [the] semiotic order" (2000, p. 177). Relational ontologies that cannot account for "the kind of otherness that is "outside' relations" (2000, p. 173) are unable to address free information-the negentropic information that the first and second motors exclude as undesirable noise. This problem is faced by both actor-network (ANT) and assemblage theories. ANT, in its reliance on 'following the actors' (Latour, 2005) requires the white arm to have not just an origin but also a destination or end. Being in relation is what permits the actor-network to emerge. The immanence of these relations facilitates the identification of assemblages or "wholes whose properties emerge from the interactions between parts" (De Landa, 2006, Introduction). For parts to interact, they have to be part of an explicit process. That which is outside the process, the interaction or the relation is excluded.

In a paradigm of resources to needs, mapping seeks to constitute a reservoir where entropy and negentropy can mingle. Free information, without value or meaning, can emerge from the combination of potentials, where each potential captures a form of meaningful information. The potential gleaned from the urban form captures the negentropic information contained within it.
Accessibility is currently actualized as such and is measurable, quantifiable. Potentiality, as opposed to potential, deals with the virtual, because it is entropy or noise out of which free information can be drawn. It is not yet actualized-the white arm has yet no receiver. It is not yet part of any particular process (which is why it cannot be 'assembled'). Rather, it is 'pre-specific' (Bühlmann, 2013 , p. 147). Mapping the potential of the urban volume locates geographically the multiplicity of this potential in a single location, but it remains indifferent where potentiality is of interest. It is a reservoir of potentiala 'space of potentiality' (Wolf \& Mahaffey, 2016) - from which potentiality can be drawn as unheard melodies or harmonies in the noise of possibility.

\section{Conclusion: Co-producing Differentiations of the Urban Mass}

The paradigm of 'resources to needs' has been promoted by the Deep City project at the EPFL in Switzerland since 2005. As opposed to a method of mapping underground potential, which has evolved extensively through a variety of case studies around the world, the theoretical framework of the research program has engaged little with urban theory and philosophy. This article began by examining the resources to needs paradigm as a claim for constituting underground potential prior to necessity, referring to the work of biologist Jacques Monod and physicist Léon Brillouin. Looking at the underground as it has been addressed in city models and within the vectorial, transformational and informational motors of Michel Serres revealed that the underground is excluded because it is considered outside of given or necessary relationships. The first two motors tend to characterize the way in which the mechanical and ecological normative models are founded upon functionalist concerns with processes, relations and fixed identities of elements. The informational motor, on the contrary, in its logic of substitution and mixture of elements without fixed identities or relations is better suited to constitute a reservoir of potentiality that is an intermediate point between resources and the needs of an urban agglomeration.

The operationalization of mapping within a paradigm of resources to needs is being worked out in more detail elsewhere (Doyle, 2016b), but some directions can be sketched out here. The map of underground potential as an orthography is not a message from geologists or engineers to be received passively by urban planners. Rather, it seeks to establish a closer collaboration across disciplinary boundaries and circulates in order to destabilize and stabilize a planning collective. This collective is founded upon the urban volume and concerns geologists, engineers, architects and urban planners, and so on-as a community of the urban volume. It is a community that calls for co-production, as Wolf and Mahaffey (2016) describe in a recent article, and not simply participation (which implies taking on pre-defined or fixed roles). As such, potential as it is mapped in abstraction 
and prior to needs is an economy of communication that, downstream, undergoes the differentiating and articulation process of society and politics. Questions can be asked: What do we do with this potential? Preserve it for the future? Harness it now? The mapping, as it is proposed here, can only aid in working through these questions-it does not provide the answer.

In developing the resources to needs paradigm, the Deep City project pointed out the limits of the status quo-identifying needs (projects, plans, problems) and exploiting resources to execute or solve them. While this article recognizes recent advances in mapping underground potential (even on the Deep City project) as increasingly embracing a wider conception of the urban volume as comprised of multiple resources in interaction, it nevertheless offers several words of caution. The increasing availability of detailed data on the underground may give a false sense of certainty about ground conditions. Much aggregate information, from maps to 3D models is based on interpolation algorithms. Such accuracy, as Brillouin demonstrates, must be paid for in uncertainty, in that which chosen measures exclude or obscure. The mapping methods described here combine multiple sources of data either using expert opinion or a multi-criteria method like the AHP, thereby enabling the evaluation process to be specific about underground space potential, but at the expense of other resources. Experience has shown that neglecting potential interactions with other resources can lead to undesirable conflicts and untapped synergies (Blunier, 2009; Parriaux et al., 2010).

Finally, this article has focused on underground resources and on urban form, because it was in this context that the resources to needs paradigm was proposed. The larger philosophical questions posed however by the work of Michel Serres, Jacques Monod and Léon Brillouin challenge urban planning and architecture to reflect on the role of contingency and chance in a world dominated by and oriented towards necessity. ${ }^{22}$ The fact that these questions stem from observations made outside the social sciences (yet are highly relevant for them, as Serres's body of work can attest) only highlights the importance of accounting for that which is outside language (Iogos) - in the ichnography, the entropic, the mass and the material. From the entropic, governed only by the law of chance, the radically new and improbable emerges (Monod, 1972; Serres, 1977/2000). As Monod claims, the irrationality of the improbable can be captured by rational forms of reasoning (for instance, principal component analysis in identifying concrete universals). Heterotopiality is a way the urban already tries to cope with the desire and the threat of the irrational (Shane, 2005). Can we preserve this noise? Make room for the improbable? Can uncertainty be creatively harnessed by the planning and design process? Or will we continue to condemn the noise of the urban volume to silence?

\section{Acknowledgments}

The author would like to thank the editors and three anonymous reviewers for their comments in helping to improve the paper.

\section{Conflict of Interests}

The author declares no conflict of interests.

\section{References}

Agamben, G., \& Heller-Roazen, D. (1999). Potentialities: Collected essays in philosophy. Stanford, CA: Stanford University Press.

Alexander, C. (1977). A pattern language: Towns, buildings, construction. Oxford: Oxford University Press.

Bélanger, P. (2016). Altitudes of urbanization. Tunnelling and Underground Space Technology, 55, 5-7. doi: 10.1016/j.tust.2015.09.011

Blunier, P. (2009). Méthodologie de gestion durable des ressources du sous-sol urbain (Doctoral Dissertation). EPFL, Lausanne, Switzerland. Retrieved from http://library.epfl.ch/theses/?nr=4404

Bobylev, N. (2009). Mainstreaming sustainable development into a city's Master plan: A case of urban underground space use. Land Use Policy, 26(4), 1128-1137. doi:10.1016/j.landusepol.2009.02.003

Bobylev, N., \& Sterling, R. (2016). Urban underground space: A growing imperative. Tunnelling and Underground Space Technology, 55, 1-4. doi:10.1016/ j.tust.2016.02.022

Brenner, N., \& Schmid, C. (2015). Towards a new epistemology of the urban? City, 19(2-3), 151-182. doi: 10.1080/13604813.2015.1014712

Brillouin, L. (2013). Science and information theory. Mineola, NY: Dover Publications. (Original work published 1962)

Bühlmann, V. (2013). Primary abundance, urban philosophy-Information and the form of actuality. In V. Bühlmann \& L. Hovestadt (Eds.), Printed physics: Metalithikum I (pp. 114-154). Vienna: Springer.

BühImann, V. (2016a). Architectonic disposition: Ichnography, scænography, orthography. In R. Braidotti \& M. Hlavajova (Eds.), The posthuman glossary (p. Forthcoming). London: Bloomsbury.

Bühlmann, V. (2016b). Negentropy. In R. Braidotti \& M. Hlavajova (Eds.), The posthuman glossary (p. Forthcoming). London: Bloomsbury.

Cannigia, G., \& Maffei, G. L. (2001). Architectural composition and building typology: Interpreting basic building. Florence, Italy: Alinea. (Original work published 1987)

Corner, J. (2002). The agency of mapping: Speculation, critique and invention. In D. E. Cosgrove (Ed.), Mappings (pp. 214-300). London: Reaktion Books.

22 See, for instance, Serres's essay Trahison: La Thanatocratie in La Traduction (1968, pp. 73-104). 
Cuddington, K. (2001). The "balance of nature" metaphor and equilibrium in population ecology. Biology and Philosophy, 16(4), 463-479. doi:10.1023/ A:1011910014900

De Landa, M. (2006). A new philosophy of society: Assemblage theory and social complexity. London and New York: Continuum.

Dovey, K. (2010). Becoming places: Urbanism/architecture/identity/power. London and New York: Routledge.

Doyle, M. R. (2016a). From hydro/geology to the streetscape: Evaluating urban underground resource potential. Tunnelling and Underground Space Technology, 55, 83-95. doi: 10.1016/j.tust.2016.01.021

Doyle, M. R. (2016b). Potentialities of the urban volume: Mapping underground resource potential and deciphering spatial economies and configurations of multi-level urban spaces (Doctoral dissertation in Architecture and the Sciences of the City). EPFL, Lausanne, Switzerland.

Doyle, M. R., Thalmann, P., \& Parriaux, A. (2016). Underground potential for urban sustainability: Mapping resources and their interactions with the deep city method. Sustainability, 8(9), 830. doi:10.3390/ su8090830

Düppe, T. (2011). The making of the economy: A phenomenology of economic science. Lanham, MD: Lexington Books.

Easterling, K. (2014). Extrastatecraft: The power of infrastructure space. Brooklyn, NY: Verso.

Ellerman, D. (2014). On concrete universals: A modern treatment using category theory. SSRN Electronic Journal. doi:10.2139/ssrn.2435439

Hénaff, M. (2008). La ville qui vient. Paris: I'Herne.

Hénard, E. (1982). Etudes sur les transformations de Paris, et autres écrits sur l'urbanisme. Paris: L'Equerre. (Original work published 1903)

Hetherington, K., \& Lee, N. (2000). Social order and the blank figure. Environment and Planning D: Society and Space, 18(2), 169-184. doi:10.1068/d215t

Hillier, B. (2007). Space is the machine: A configurational theory of architecture. Cambridge: Cambridge University Press. (Original work published 1996)

Hillier, B. (2009). Spatial sustainability in cities: Organic patterns and sustainable forms. In D. Koch, L. Marcus, \& J. Steen (Eds.), Proceedings of the Seventh International Space Syntax Symposium (pp. K01.1-K01.20). Stockholm: Royal Institute of Technology.

Hillier, B., \& Hanson, J. (1984). The social logic of space. Cambridge: Cambridge University Press.

Hillier, B., Turner, A., Yang, T., \& Park, H.-T. (2010). Metric and topo-geometric properties of urban street networks: Some convergences, divergences and new results. Journal of Space Syntax, 1(2), 258-279.

Koch, D. (2016). On avoidance: Reflections on processes of socio-spatial structuring. Civil Engineering and Architecture, 4(2), 67-78. doi:/10.13189/ cea.2016.040204
Kuitert, W. (2013). Urban landscape systems understood by geo-history map overlay. Journal of Landscape Architecture, 8(1), 54-63. doi:10.1080/ 18626033.2013.798929

Latour, B. (2005). Reassembling the social: An introduction to actor-network-theory. Oxford: Oxford University Press.

Le Moigne, J. L. (1977). La théorie du système général: Théorie de la modélisation. Paris: Presses Universitaires de France.

Li, H., Li, X., Parriaux, A., \& Thalmann, P. (2013). An integrated planning concept for the emerging underground urbanism: Deep City Method Part 2 case study for resource supply and project valuation. Tunnelling and Underground Space Technology, 38, 569580. doi:10.1016/j.tust.2013.04.009

Li, X., Li, C., Parriaux, A., Wu, W., Li, H., Sun, L., \& Liu, C. (2016). Multiple resources and their sustainable development in Urban Underground Space. Tunnelling and Underground Space Technology, 55, 5966. doi:10.1016/j.tust.2016.02.003

Lu, Z., Wu, L., Zhuang, X., \& Rabczuk, T. (2016). Quantitative assessment of engineering geological suitability for multilayer Urban Underground Space. Tunnelling and Underground Space Technology, 59, 6576. doi:10.1016/j.tust.2016.06.003

Lynch, K. (1960). The image of the city. Cambridge, MA: MIT Press.

Marcus, L. (2010). Spatial capital: A proposal for an extension of space syntax into a more general urban morphology. Journal of Space Syntax, 1(1), 30-40.

McHarg, I. L. (1969). Design with nature. Garden City, NY: Published for the American Museum of Natural History by the Natural History Press.

Moffatt, S., \& Kohler, N. (2008). Conceptualizing the built environment as a social-ecological system. Building Research and Information, 36(3), 248-268. doi:10.1080/09613210801928131

Monod, J. (1972). Chance and necessity: An essay on the natural philosophy of modern biology. New York: Vintage Books.

Moudon, A. V. (1994). Getting to know the built landscape. In K. A. Franck \& L. H. Schneekloth (Eds.), Ordering space: Types in architecture and design (pp. 289-311). New York: Van Nostrand Reinhold.

Ortiz-Zamora, D., \& Ortega-Guerrero, A. (2010). Evolution of long-term land subsidence near Mexico City: Review, field investigations, and predictive simulations: Long-term land subsidence. Water Resources Research, 46(1). doi:10.1029/2008WR007398

Parriaux, A., Blunier, P., Maire, P., Dekkil, G., \& Tacher, L. (2010). Projet deep city: Ressources du sous-sol et développement durable des espaces urbains. Lausanne: vdf Hochschulverlag AG andETH Zürich.

Parriaux, A., Tacher, L., \& Joliquin, P. (2004). The hidden side of cities-Towards three-dimensional land planning. Energy and Buildings, 36(4), 335-341. doi:10.1016/j.enbuild.2004.01.026 
Payot, D. (1982). Le philosophe et l'architecte: Sur quelques déterminations philosophiques de l'idée d'architecture. Paris: Aubier Montaigne.

Peng, J., Wang, Y., \& Peng, F. (2014). Evaluation of underground space resource for urban master plan in Chanzhou City. In Underground space: Planning, administration and design challenges (pp. 30-35). Seoul, South Korea.

Pickett, S. T. A., Cadenasso, M. L., \& Grove, J. M. (2004). Resilient cities: Meaning, models, and metaphor for integrating the ecological, socio-economic, and planning realms. Landscape and Urban Planning, 69(4), 369-384. doi:10.1016/j.landurbplan.2003.10.035

Poore, B. S., \& Chrisman, N. R. (2006). Order from noise: Toward a social theory of geographic information. Annals of the Association of American Geographers, 96(3), 508-523. doi:10.1111/j.1467-8306. 2006.00703.x

Portugali, J. (2011). Complexity, cognition and the city. Heidelberg: Springer.

Rowe, C., \& Koetter, F. (1978). Collage city. Cambridge, MA: MIT Press.

Saaty, T. L. (1980). The analytic hierarchy process: Planning, priority setting, resource allocation. New York: McGraw-Hill.

Saaty, T. L. (1990). How to make a decision: The analytic hierarchy process. European Journal of Operational Research, 48(1), 9-26. doi:10.1016/03772217(90)90057-I

Saaty, T. L., \& Vargas, L. G. (2012). Models, methods, concepts \& applications of the analytic hierarchy process (2nd ed.). New York: Springer.

Saaty, T. L., \& Vargas, L. G. (2013). Sensitivity analysis in the analytic hierarchy process. In T. L. Saaty \& L. G. Vargas, Decision making with the analytic network process (Vol. 195, pp. 345-360). Boston, MA: Springer US. Serres, M. (1968). La traduction. Paris: Éditions de Minuit. Serres, M. (1977). La distribution. Paris: Editions de Minuit. Serres, M. (1982). Genèse. Paris: B. Grasset.

Serres, M. (1982). The parasite. (L. R. Schehr, Trans.). Baltimore: Johns Hopkins University Press. (Original work published 1980)
Serres, M. (1990). Le système de Leibniz et ses modèles mathématiques: Etoiles, schémas, points (3. éd.). Paris: Presses Univ. de France.

Serres, M. (1993). Les origines de la géometrie: Tiers livre des fondations. Paris: Flammarion.

Serres, M. (2000). The birth of physics. Manchester: Clinamen Press. (Original work published 1977)

Serres, M. (2015). Rome: The first book of foundations. London: Bloomsbury Academic (Original work published 1983)

Serres, M. (2015). Statues: The second book of foundations. (R. Burks, Trans.). London: Bloomsbury. (Original work published 1987)

Shane, D. G. (2005). Recombinant urbanism: Conceptual modeling in architecture, urban design, and city theory. Chichester: Wiley.

Shane, D. G. (2011). Transcending type: Designing for urban complexity. Architectural Design, 81(1), 128-134. doi:10.1002/ad.1197

Vähäaho, I. (2009). Underground masterplan of Helsinki: A city growing inside bedrock (Extract from the Underground Masterplan of Helsinki). Helsinki: City of Helsinki.

Viganò, P. (1999). La città elementare. Milano: Skira.

Wallace, M., Roberts, K. J., \& Lau, V. (2014). A geographic information systems approach for regional cavern suitability mapping for Hong Kong. In Underground space: Planning, administration and design challenges. Seoul, South Korea.

Williams, R. (2008). Notes on the underground: An essay on technology, society, and the imagination. Cambridge, MA: MIT Press. (Original work published 1990)

Wolf, G., \& Mahaffey, N. (2016). Designing difference: Coproduction of spaces of potentiality. Urban Planning, 1(1), 59-67. doi:10.17645/up.v1i1.540

Zhao, J.-W., Peng, F.-L., Wang, T.-Q., Zhang, X.-Y., \& Jiang, B.-N. (2016). Advances in master planning of urban underground space (UUS) in China. Tunnelling and Underground Space Technology, 55, 290-307. doi: 10.1016/j.tust.2015.11.011

\section{About the Author}

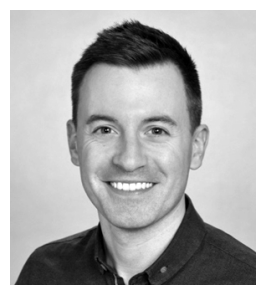

Michael R. Doyle is currently a postdoctoral researcher at both the Department of Architectural Theory and the Philosophy of Technics at TU Vienna and the Laboratory of Environmental and Urban Economics at the EPFL in Switzerland (where he earned his PhD in 2016). His research interests revolve around novel sources of information for the design and planning process, from the material (geology, built form) resources of the urban volume to the evolving influences of mobile technology on spatial practices. 